\title{
Article
}

\section{Friend or Foe: Towards a Critical Assessment of Direct Payments}

\author{
Spandler, Helen
}

Available at http://clok.uclan.ac.uk/525/

Spandler, Helen ORCID: 0000-0002-0970-5141 (2004) Friend or Foe: Towards a Critical Assessment of Direct Payments. Critical Social Policy, 24 (2). pp. 187-209. ISSN 02610183

It is advisable to refer to the publisher's version if you intend to cite from the work. http://dx.doi.org/10.1177/0261018304041950

For more information about UCLan's research in this area go to

http://www.uclan.ac.uk/researchgroups/ and search for < name of research Group>.

For information about Research generally at UCLan please go to http://www.uclan.ac.uk/research/

All outputs in CLoK are protected by Intellectual Property Rights law, including Copyright law. Copyright, IPR and Moral Rights for the works on this site are retained by the individual authors and/or other copyright owners. Terms and conditions for use of this material are defined in the policies page.

\section{CLoK}

Central Lancashire online Knowledge www.clok.uclan.ac.uk

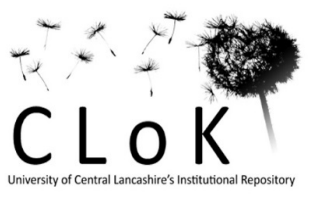




\title{
Friend or foe? Towards a critical assessment of direct payments
}

\begin{abstract}
Direct payments enable individuals to purchase their own care rather than have directly provided services. This article unpacks the complexities involved in the implementation of direct payments by addressing the need to reconcile the strong evidence of their benefits with emerging concerns about the wider consequences of their implementation. One practice that highlights the conflicts at the heart of direct payments is the employment of personal assistants. While directly employing personal assistants offers maximum benefit for recipients, it also produces the strongest concerns. Therefore, an understanding of the context of direct payments, specifically the practice of employing personal assistants, is used to explore these complexities in greater depth. The discussion concludes by arguing for a more critical awareness of the wider context in which direct payments are being developed in order to understand how this context can open up or limit opportunities for greater self-determination. It suggests a number of factors that need to be addressed to ensure that direct payments continue to be a progressive strategy. These include reconciling conflicting ideologies such as those advocating individual choice and/or collective provision; the need for political action to secure adequate resources; and the development of alternative strategies such as cooperatives to address the collective needs of direct payment recipients and workers.
\end{abstract}

Key words: consumerism, cooperatives, personal assistants, selfdetermination, user movement

\section{Introduction}

Direct payments (DPs) are paid by a local authority to individuals who are assessed as requiring community care services and are deemed 
willing to accept and able to manage the payments alone or with assistance (DoH, 1996). The local authority makes the payments to the individual (or a user-controlled trust) instead of directly providing services. The individual then uses the payments to secure the support or assistance that they feel most appropriately meets their needs.

The key problem this article addresses is how to reconcile the growing evidence of the benefits that using DPs has brought to recipients with important concerns about their continued development and expansion in social policy. In attempting to answer this question, I argue that we need to separate out the more progressive arguments both for and against DPs from more reactionary arguments. I refer to progressive strategies as those that increase the possibilities of greater self-determination and that address the needs of recipients and workers. Reactionary arguments against DPs include fear of change, risk aversion, an over-reliance on traditional and established ways of working, paternalism, overprotection, institutionalization and professional resistance to giving up control and power. Reactionary support for DPs might arise from a desire to get rid of 'difficult' clients, cost-cutting and current new right $/ \mathrm{New}$ Labour concerns about 'welfare dependency'. To move beyond a polarized debate towards a critical assessment of the potential of DPs, I explore the arguments of proponents and critics of DPs that primarily arise from 'progressive' positions. By doing this, I hope to contribute towards a critical assessment of DPs as a progressive social policy initiative.

\section{Background}

Any debate about DPs must understand the context of its emergence. This includes the philosophy of independent living, the social model of disability and critiques of the medical model. In the UK, the pressure for DPs arose, in part, via campaigning by organizations of disabled people. Many independent living centres, offering support to recipients, have been set up in areas where there has been strong and effective campaigning by local organizations of disabled people (Stainton and Boyce, 2002). The notion of self-determination advocated by the independent living movement does not assume that people could necessarily meet their needs alone, but rather 'with assistance' (Morris, 1997). DPs can enable this assistance, and reci- 
pients frequently use the money to employ their own personal assistants (PAs); indeed, although people may choose to meet their needs in a variety of ways, employing and directing PAs has always been at the heart of demands for DPs (Campbell, 1998; Glasby and Littlechild, 2002; Zarb and Nadash, 1994).

In principle, if not in practice, giving cash in lieu of services is 'now officially accepted and endorsed' (Glendinning et al., 2000c: 11). However, the slow pace of implementation is frequently seen as a concern for many user organizations and government (Witcher et al., 2000). Direct payments are now being increasingly pushed by government policies (DoH, 2001a, b, 2003). In the UK, until 2002, local authorities were given 'discretion' in implementing DPs, making their implementation dependent upon local politics of service provision (Pearson, 2000). However, new legislation (enforceable from April 2003) makes it mandatory for local authorities to offer DPs as an option (DoH, 2001a, 2002).

While legislation has made DPs possible across care groups, takeup has, until recently, been primarily confined to adults with physical disabilities. However, their successful implementation has increasingly led to demands that take-up be actively promoted and increased to other user groups such as elderly people, people with learning disabilities or mental health needs, carers and younger people (Bamber, 2002; Evans, 2000; Holman and Bewley, 1999). There are also increasing demands to extend the provision of DPs into health as well as social care (Glendinning et al., 2000c).

Finding appropriate terminology for recipients of DPs is difficult. Despite DPs being available to various client groups, many commentators refer to DP recipients as 'disabled people' (see, for example, Glasby and Littlechild, 2002). This term may be inadequate for other clients such as those with mental health needs. Other possible terms include employer, service user, PA user or customer. However, none of these terms sufficiently captures the complexity of an arrangement that simultaneously places the 'service user' in a position of also being the purchaser and the possible employer. It is this very complexity that highlights some of the conflicts at the heart of the development of DPs. O'Brien (2001) argues that the success of individualized funding initiatives should be measured by the rate of transition from consumer to agent; in other words, how far they generate active and creative negotiators or 'agents' rather than simply reproduce passive consumers. In the absence of a sustained assessment of this transition 
or a corresponding shift in terminology, I use the term 'recipient'. This term identifies an individual's receipt of payments, irrespective of how they decide to use the money and/or how 'successful' it is.

\section{Contextual conflicts}

The rise of DPs is also linked to other broader political changes. In the drive to introduce market forces and managerialism into welfare services, the new right seized upon people's dissatisfaction with the welfare state, particularly its insensitivity to individuals' needs and differences, its heavy-handed statism and its bureaucracy (Harris, 1999). In attempts to dismantle the welfare state, the new right 'skilfully appropriated a diverse set of challenges to state welfare provision and articulated them around the rhetoric of producer versus consumer choice' (1999: 921). This agenda converged with welfare user movements' growing concerns and critiques about inadequate and insensitive services.

Subsequently, New Labour's focus on community politics and local ownership has also made concessions to the importance of market forces in its development of a 'Third Way' (Beresford, 2002). During the 1990s, this ushered in a 'new consensus' on the importance of the individual consumer-citizen which implicitly undermined any political or collective aspects of social citizenship. DPs highlight this new consensus as a convergence of the concerns of social justice and market consumerism (Pearson, 2000).

The history of DPs has therefore comprised a complex confluence of new right, New Labour and welfare user movement ideologies and demands. However, because of the diverse ideologies this consensus has incorporated, tensions and conflicts remain, but are frequently implicit and uncontested (Pearson, 2000). This confluence has shaped the development of DPs, in terms of their implementation and impact, and has resulted in a range of difficulties and conflicts. Most importantly, these conflicting agendas can actually limit the extent to which DPs can deliver greater self-determination (Pearson, 2000; Stainton, 2002). It is precisely assumptions of common interests and the denial of conflict that cloud the debate about DPs and lead to the potential benefits of DPs being unrealizable (O'Brien and O'Brien, 1999); indeed, Dowson (2002) argues that it is necessary to clarify 
conflicts of interest in practice rather than pursuing policies that assume the importance of 'joint working' and 'partnerships'.

Furthermore, these conflicts have led to polarized reactions, whereby protagonists are either for or against DPs. This atmosphere has prevented a real assessment of the possibilities and limitations of DPs. For example, Ungerson (1997) highlights how DPs, and specifically employing PAs, have been seen by the disability movement as a panacea and is critical of how DPs are frequently only viewed as positive. However, it has also been pointed out that critics tend to overstate their opposition (Glendinning et al., 2000a). For example, Ungerson describes DPs' services as 'goods of limited and contested utility' (1997: 51). On the other hand, advocates of DPs (see, for example, Witcher et al., 2000) argue that any reaction against DPs can only stem from a fear of change.

Another consequence of the conflicting motivations for DPs is the potentially conflicting interests of workers and recipients. While disability activists have tended to advocate DPs, trade unions have been more cautious. Demands from welfare user movements can at times appear to conflict with demands from the labour movement, resulting in what Lewis describes as a 'welfare trade off' (Lewis, 1998); indeed, welfare users' dissatisfaction with how professionals ignored their individual needs, rights and choices was one aspect of policy that the new right exploited during its long reign. More recently, conflict between workers and users can be illustrated by a high court judgement that ruled that local authorities cannot enforce a policy that prohibits care workers from manually lifting clients for health and safety reasons (Zarb, 2003). This has been viewed as an important victory for the disability movement, which views using hoists as disregarding human rights and personal dignity. However, a recent survey of home care workers reported that 10 percent more of its members report back pain than the rest of the adult population (UNISON, 2001).

\section{Proponents of DPs}

Grand claims have been made about the benefits of DPs. The Community Care (Direct Payments) Act (DoH, 1996) has been described as the realization of 20 years of collective advocacy (Campbell, 1998). It is hoped that DPs might represent a shift of a 
similar magnitude to that from institutional care to community care. At the very least, implementing DPs has the capacity to change the whole focus of community care provision. For those who have yet to reap the benefits of DPs, such as mental health service users, DPs have been described as a 'silent victory' whose time will come (Maglajlic et al., 1998: 33). In the field of learning difficulties, DPs have been described as the single most empowering piece of legislation for people ... that has ever been passed onto the statute books' (Holman, 1999: 3). DPs are viewed as a major step towards a redistribution of power and resources, providing a way that disabled people can wrest control of services away from local authorities into their own hands. DPs offer a 'unique' (Glendinning et al., 2000c: 11) and 'potentially revolutionary' (Glasby and Littlechild, 2002: 137) challenge to the historically unequal relationship between providers and receivers of care (Campbell, 1998).

For many disabled organizations, DPs are seen as the key to the expression and realization of the fundamental human right to have the support necessary to exercise self-determination, choice, independence and control (Campbell, 1997; Hasler et al., 1999; Morris, 1993). Stainton (2002) argues that DPs are potentially a major step towards a structural rights-based model for social work practice. DPs are seen by many as an important stage in the achievement of a civil rights movement. Typically, Morris claims that the 'struggle for direct payments has been a struggle against segregation' (1997: 58). In an impassioned account of its history, Campbell (1998) compares the first people who demanded DPs with Rosa Parks refusing to give up her seat to a white man, an act widely seen as kick-starting the black civil rights movement in the US (Morris, 1997).

Specifically, DPs are viewed as facilitating people to live in the ways that they choose rather than being given services to match preconceived assumptions about what is needed and how individuals should live. DPs provide greater flexibility and reliability over when, how and who provides the support that people need (Halliwell and Glendinning, 1998; Stainton and Boyce, 2002). As a consequence, DPs have the potential of developing more creative and innovative ways of providing assistance (Torjman, 1996).

These claims are extremely compelling. Furthermore, they seem to be supported by people's actual experience of receiving DPs. Evaluations of DPs report a very high recipient satisfaction rate, particularly in comparison to conventional services (see, for example, 
Glendinning et al., 2000c; Halliwell and Glendinning, 1998; Kestenbaum, 1999; Morris, 1993; Stainton and Boyce, 2002; Witcher et al., 2000; Zarb and Nadash, 1994). The most important aspect of this satisfaction seems to be the opportunity to exercise choice and control over support arrangements (Stainton and Boyce, 2002; Witcher et al., 2000). As a consequence, many recipients report positive benefits to their quality of health and social life (Glendinning et al., 2000b). These benefits often derive from increased opportunities for social activities and social support (Glendinning et al., 2000a). Recipients report enhanced personal autonomy, emotional and psychological wellbeing, raised opportunities and a greater quality of life (Carmichael and Brown, 2002; Glendinning et al., 2000a; Stainton and Boyce, 2002; Witcher et al., 2000). Most recipients identify very few, if any, disadvantages to DPs (see Witcher et al., 2000). Where recipients do identify problems, these generally relate to aspects of policy or practice in particular authorities rather than to DPs per se (Witcher et al., 2000).

Even more revealing is the fact that recipients often speak of their experience of DPs in emancipatory language (Stainton, 2002). Some proponents of DPs have speculated that the extension of DPs may challenge both the inflexible pattern of much traditional service provision and public prejudice. Growth in recipients' confidence and assertion may also lead to demands for increased civil rights and a greater ability to participate in community and political forums (Witcher et al., 2000). In addition, benefits have also been noted in individuals' social networks, for example by allowing familial and other relationships to be freed from carer responsibilities (Witcher et al., 2000).

Another benefit is the more thorny issue of cost savings. The largest and most influential study of cost effectiveness argues that DPs are more cost effective than conventional services (Zarb and Nadash, 1994). Services arranged via DPs are almost invariably cheaper than more traditional forms of service delivery offering equivalent hours of support. User-controlled money, it is argued, goes further. Powerful personal incentives exist for recipients to use their money wisely, efficiently and prudently because their survival and independence depend upon it (Zarb, 1998). In addition, because the user often acts as an employer and budget holder, he/she soaks up much of the administrative and management costs. This may mean that recipients can get greater levels of social care at no greater cost. 
While the various benefits outlined above suggest that DPs are a compelling alternative, they have not been developed without criticism. In the following section, I review some of the more important criticisms that have emerged since their inception.

\section{Critiques of DPs}

The lure of possible cost-cutting has resulted in some commentators being wary of the greater extension of DPs. For example, Canadian National Union Research expresses concern that the 'overwhelming justification for these types of funding schemes appears to be costsavings to the system' (National Union Research, 2000: 6). However, given the benefits of DPs, opposition merely on the basis of costcutting is inadequate. On the other hand, it is too premature to argue that 'all reasonable arguments against it have been demolished . . . it would be a foolish waste of time to repeat that process' (Campbell, 1997: 23).

Much of the literature in the UK has focused on 'reactionary' concerns about DPs such as fear of change, risk aversion and paternalism. This focus has resulted in recommending strategies to overcome professional resistance to their implementation. It is frequently reported that the only difficulties that recipients experience with DPs are those relating to bureaucracy, paperwork and administration. Such problems, it is argued, can be solved, or at least eased, by support services such as independent living centres. While important, this focus has resulted in little acknowledgement of other more fundamental and complex difficulties (Glasby and Littlechild, 2002; Ungerson, 1997).

This lack of critical analysis and reflection may be partly due to the relatively recent take-up of DPs in the UK compared with the US and Canada, where more critiques and debates have emerged (see National Union Research, 1998, 2000; O’Brien, 1999, 2001). Most critiques do recognize that, on the whole, DPs are more satisfactory to recipients (for example, National Union Research, 2000; Ungerson, 1997). However, they remind us that DPs are not necessarily a straightforward 'march of progress' towards the adoption and promotion of progressive social policy.

Critics argue that calls for DPs interrupt important debates about collective service provision (O'Brien, 2001). In particular, DPs cannot 
replace long-term investment in a solid, publicly-funded and accountable welfare infrastructure (Torjman, 1996). Ultimately, DPs are perceived as a threat to a healthy and vibrant public sector that collectively develops best practices and standards in the provision of support (National Union Research, 2000). A review of recent social policies that give public service consumers more 'choice' suggests that, while short-term individual user satisfaction may increase and general efficiency may improve, wider goals of responsiveness and experimentation are not so easily achieved $(6,2003)$.

More specifically, critics have questioned how DPs can contribute to the evolution of services to meet the needs of groups of individuals who have similar difficulties (National Union Research, 1998). DPs do not guarantee the development of new and specialized services, nor do they necessarily respond in a coherent way to the changing and dynamic needs of groups and communities rather than just individuals (National Union Research, 1998). O'Brien (2001) questions whether individualized funding will drive the changes necessary to develop highly customized services. By developing services one at a time for individuals who decide to 'opt out' of mainstream services, DPs can become an excuse for avoiding the development work necessary to make services resourced, flexible and responsive to individuals' changing needs (O'Brien and O'Brien, 1999).

DPs may offer alternative ways of providing more culturally appropriate services by ensuring that people can employ suitable PAs that understand their specific cultural needs (Begum, 1992; Brown, 1999). This may provide more individualized support and cut across boundaries such as health/social (Glendinning et al., 2000c) or gender/culture (Burman et al., 2002) which frequently impede service accessibility. However, the privatization of care that this necessitates will not necessarily feed into the development of 'culturally appropriate' communal services that address the intersections between race, gender, class, sexuality and disabilities. In addition, it may militate against an understanding of the wider structural context in which oppression is experienced. Such understanding may otherwise be possible through teamworking, sharing information and supervision. In addition, although research is necessary to investigate the class background of DP recipients, it may be that more educated, articulate and primarily middle-class individuals are able to take advantage of the opportunities offered through DPs. 
Another concern relates to the possible effects of DPs on the emergence and viability of collective self-help movements. DPs might circumvent processes of community development and self-help by removing the possibilities of developing self-help initiatives. The individual nature of DPs could remove those most likely to initiate new challenges, especially dissatisfied people with seemingly 'marginalized' needs who might otherwise be able to voice and address new collective responses. In addition, although there is some evidence that DPs facilitate greater social support for individuals, there is still a concern that DPs are overly individualistic and could invite or reproduce isolation (Torjman, 1996).

The concern about the underlying individualization of DPs has emerged particularly in relation to the perceived limits of individual consumer choice. This suggests that the option of being an individual paying customer and exercising individual choice is actually illusory in terms of genuine empowerment. O'Brien argues that, while the idea of becoming paying customers excites people, the 'metaphors that excite enthusiasm' need careful scrutiny (O'Brien, 2001: 2). The discourse of consumerism may be seductive particularly because paying customers hold a more valued role in consumer society than do beneficiaries of welfare services. Consumers can be seen as providing the 'heat that paying customers can apply to unfreeze a system stuck in controlling people' (2001: 2). This compelling image of the paying customer mobilizes many people who are dissatisfied by the current welfare system's inability to deliver the assistance that people need. However, despite the official endorsement of concepts such as choice, individual budgeting and person centredness, it is questionable whether this necessarily results in a wider power shift. For example, O'Brien (1999) argues that despite the growth of individualized funding schemes, the number of real allies of disabled people among service managers, politicians and civil servants has actually decreased. In addition, in the US, 'consumer choice' has been used to mask other reactionary policy agendas such as welfare cuts (Henig, 1994).

This relates to the way that DPs' proponents have been accused of misunderstanding how the market works under capitalism because market forces actually provide a poor impetus for service provision (National Union Research, 2000; Torjman, 1996). DPs engage the contradictions of creating an equal market within an underfunded bureaucratic welfare system (O'Brien, 2001: 6). While powerful images of individuals choosing their own support from available 
resources might sound compelling, the reality of the market may be less rewarding. Neoliberal policy analysts and rightwing political theorists have advocated individualized funding-type policies in many areas of public policy. However, these have not necessarily been successful in delivering quality services, social justice or equality - the principles on which DPs are based. For example, in the education system, exercising individual 'choice' has, in some areas, at least in the short term, resulted in greater segregation, widening gaps in performance and the development of an elite subsector (see 6, 2003; Fiske and Ladd, 2000; Gorard and Taylor, 2002; Noden, 2000).

The ways in which consumerist policies reproduce assumptions and myths about the market can have important consequences. Pearson (2000) argues that, while a focus on the market and consumerism may have provided the initial motivation for DPs, the extent of their progressive impact has been restricted in practice by local authorities' own market concerns. An emphasis on market discourse can result in an overdominance of cost-efficiency concerns, resulting in heavy-handed attempts to 'account' for user spending. This substantially weakens the scope for user control and erodes its ability to engender stronger notions of social justice (Pearson, 2000).

Moreover, with individuals being increasingly charged for community care services (Bennett, 1996), the development of DPs could be seen as a slippery slope to greater privatization and the penetration of market forces into an already depleted welfare state. Welfare services may become increasingly based on people's ability to pay (National Union Research, 1998). Furthermore, the increasing tightening up of eligibility criteria for community care services, due to further cuts in welfare provision, will also impact on DPs (Hasler, 1999). Kestenbaum (1999) highlights the way in which many services that individuals may want to set up via DPs are precisely those that will be given lower priority because of local authority resource constraints. Freeing up DPs from the limitations of community care assessments, eligibility criteria and charging raises questions of equity - something of which recipients are very aware (Glendinning et al., 2000c).

More concrete concerns about DPs arise from the specific effects of the marketization of welfare. These draw attention to poor working conditions, low pay, safety issues and the lack of consistent, good quality service providers (National Union Research, 1998, 2000). For example, Witcher et al. (2000) found a very low rate of pay for some 
PAs and a very wide variation in rates of pay and employment conditions between local authorities for PAs. These rates were frequently well below those offered by some independent agencies or social services. In addition, they found that only a minority of local authorities paid PAs enhanced rates for unsociable hours. Because of these difficulties, DP recipients experienced problems recruiting PAs (Carmichael and Brown, 2002; Witcher et al., 2000) and worker turnover rates could be high, resulting in a lack of continuity (National Union Research, 2000). These difficulties may have a disproportionate impact on groups traditionally marginalized in the workforce by providing cheap labour, such as women (National Union Research, 1998; Ungerson, 1997; UNISON, 2001) and people from black and minoritised ethnic communities (Begum, 1992). This situation reflects a more general trend of devaluing social and home care work. A survey of home care workers, more than 97 percent of whom were women, reported receiving depleted pay levels, working (often unremunerated) unsocial hours and suffering stress, overwork and health problems (UNISON, 2001).

These specific difficulties concerning the pay and conditions of PAs relate to a more general political concern about the growth of unorganized workers and the deregulation of the workforce (National Union Research, 1998). Some critics argue that the virtual denial of organizing and collective bargaining rights for workers is one of the outcomes of DPs and possibly a major motivation for governments (National Union Research, 2000: 7). This is particularly pertinent given recent anti-union government policies and continued attacks on public sector workers. Initiatives such as DPs may be popular precisely because they have been incorporated as part of a more general project of destabilizing and weakening the power of the organized labour movement. For example, a strike by public sector home care workers in 1996 in Manioba, Canada contributed to an increased emphasis on individualized funding by the government (National Union Research, 2000). In the longer term, this may result in private companies, offering poor working conditions, emerging to supply the DP market.

In order to explore the benefits and critiques of DPs in more detail, the following section concentrates on the practice of employing PAs. This exploration enables a greater consideration of both the benefits and critiques as well as highlighting some of the specific problems concerning DPs in practice. 


\section{Conflicts in practice: employing PAs}

Although there has been a significant amount of research concerning DPs, there has been little focus on the views and experiences of PAs. Their views are important because the complex tasks, roles and relationships they negotiate play a vital role in delivering the levels of control and flexibility that recipients require (Glendinning et al., 2000a). In other words, we must analyse the context within which support or assistance operates because it is from this very context that recipients benefit (Glendinning et al., 2000c; Ungerson, 1997). This section will draw on a study that has researched the perspectives of PAs (Glendinning et al., 2000c).

Glendinning et al. (2000a) claim that, despite some problems, DP relationships may actually be mutually beneficial. They found that PAs themselves often valued being employed directly by users, particularly because of the increased quality and closeness of relationships. They argued that the direct employment of PAs 'allowed relationships to develop which, paradoxically, extended well beyond conventional employer-employee relationships' and 'contained important elements of trust, loyalty and affection which were valued by both parties' (2000a: 206). They also reported that DP relationships could bring about a subtle shift of power and make negotiation of boundaries and responsibilities easier. In addition, while direct service providers or care agencies tend to 'cream off' extra payments for care arrangements, it may be possible for DP relationships to negotiate a more generous and egalitarian distribution of money and resources.

While critiques of DPs paint a depressing picture of extreme conflict between recipients and PAs (see Ungerson, 1997), Glendinning et al. (2000a) document that, in most cases, recipients and PAs frequently shared similar concerns. These concerns included how poor working conditions, low rates of pay, low status and poor training and career opportunities adversely affected the quality of care and relationships provided via DPs. Most recipients, for example, would welcome higher DP rates so that they could increase PAs' wages (Glendinning et al., 2000a; National Union Research, 2000; Zarb and Nadash, 1994). It is therefore not necessarily the attitudes of recipients that contribute to poor employment conditions, but rather the limitations of the context in which they are forced to operate.

These shared difficulties could be alleviated by changes to the ways that DP recipients are supported and the financial arrangements 
and resources that are made available to fund DPs (Glendinning et al., 2000a). The variety and complexity of tasks undertaken by PAs and their task of developing new ways of working require a depth of responsibility and associated stress that should result in greater levels of pay, supervision and training. This would require such measures as greater funding; increased and enforceable national rates of pay and benefits for PAs; greater contingency resources; and a greater recognition of the unique work of PAs in terms of training, qualifications and career structures. In addition, it has been argued that standards of care should be agreed and enforced (National Union Research, 2000). Transferable and personalized training could be accommodated within accredited user-led training courses and opportunities provided for PAs to meet together and organize collectively (Glendinning et al., 2000a).

However, despite these shared concerns, Glendinning et al. (2000a) highlight certain aspects of PA work itself that can generate conflict between recipients and PAs. These difficulties arise from the close and often complex relationships between PAs and recipients. For example, some PAs are unsure about their job descriptions and may feel an overwhelming sense of responsibility and that unreasonable expectations are placed on them (Glendinning et al., 2000a; National Union Research, 2000). In addition, while recipients may find it hard to bring up difficult issues with their PAs, the latter, in turn, may need opportunities to talk among themselves, but this can conflict with recipients' demands for confidentiality (Glendinning et al., 2000a).

With these broader concerns in mind, alternative ways of providing DPs have been advocated that involve removing the direct employer-employee relationship and associated administrative responsibilities. National Union Research (2000) insists that a distinction needs to be drawn between self-managed care and the means by which this can be developed. It argues that self-managed care does not have to be provided by individualized funding and suggests that individualized funding is the most common model of providing selfmanaged care because it reflects current government priorities, not necessarily best practice. It argues that the benefits attributed to DPs are not necessarily dependent upon the need for the recipients to be a direct employer; indeed, it draws on evidence that users find the bureaucratic and administrative elements of this difficult. It proposes 
a brokerage or agency model, whereby a third party is responsible for employment practice, under the control of recipients.

However, as we have seen, one of the most important aspects of the success of DPs has actually been attributed to the quality of relationship between recipient and PA precisely because of the direct employment relationship. Glendinning et al. (2000a) demonstrate that removing this direct relationship actually removes a large element of the control that is crucial to improving quality of life and health via DPs (Glendinning et al., 2000; Stainton and Boyce, 2002; Witcher et al., 2000). To illustrate this, Glendinning et al. (2000a) found that such benefits were reduced when agencies provided the PAs.

A further problem arises because the solutions offered do not necessarily address the more fundamental problems that DPs themselves have evolved to address. Such problems include the historical and enduring failures, misunderstandings, pathologization and treatment of people with disabilities, learning difficulties and mental health problems. In particular, they don't address the enduring and crucial tension that DPs highlight between users, workers and carers. For example, if standards of care are agreed and enforced, there may be less room for the innovative and creative use of DPs that challenge the ways that usual standards and practices are decided upon. It is, after all, these very innovations that DPs are designed to initiate and support. Moreover, the greater the status and training that PAs receive, the more these potentially threaten the balance of power and control between the recipient and the PA - exactly what DPs are designed to redress (Glendinning et al., 2000c). This raises the issue of how care workers can be trained in 'user-centred' ways, a problem that, more generally, has not been adequately resolved.

More fundamentally, the very changes necessary to enable greater egalitarian relationships may not be possible within the economic and political culture in which DPs are currently being promoted; indeed, one of the reasons that DPs are experienced as better than conventional services is due to the greater level of input and range of tasks that PAs can perform. Glendinning et al. (2000c) document how some users receive 'health-related' care through their PAs - care that is no longer available to them on the NHS. However, because assessments and costings for DPs only include social, domiciliary and home care, the payment of PAs will continue to reflect this rather than the more intensive and demanding support that many service 
users actually require. However, this difficulty may be endemic to the changing nature of home and social care. UNISON (2001) reports that home care workers in general are being required to take on more health-related tasks. This situation raises the question of whether DPs are actually a way out of these difficulties or merely another example of them.

This section has described how, paradoxically, the employment of PAs, enabled through DPs, offers both maximum benefit for recipients and yet throws up some of the most difficult and complex dilemmas. This is mainly due to the close and direct employment relationship between recipients and PAs. Globally, society is becoming increasingly commodified and marketized and people are recognized primarily as buyers and sellers in an increasingly dehumanized and alienated marketplace. The exploitation of home and social care workers in the private sector and the increasingly marginalized, casualized and low-paid status of home care workers generally has recently led to UNISON promoting a national Crisis in Social Care campaign (2002). It seems clear that the extension of DPs must not compound this situation. More generally, it is not clear how far DPs can cultivate welfare relationships outside and against the trend of market capitalism.

\section{Critical recommendations}

Having explored some of the complexities involved in the principles and practices of DPs and specifically the employment of PAs, it seems clear that neither a simplistic pursuit of DPs as empowerment, nor a kneejerk reaction against them as merely cost-cutting consumerism is an adequate response. DPs are not clearly a 'consumerist' or a 'democratic' approach to social policy (Beresford, 2000), but actually an example of the convergence of the two, a convergence that yields both problems and possibilities. While we must take seriously the obvious benefits that DPs have brought to individuals and to the culture of welfare, responses must also accentuate the potential opportunities opened up through DPs and not just reproduce wider problems in welfare. On the basis of the analysis above, the following sections suggest some necessary conditions for DPs to continue to be a progressive strategy. 


\section{a) Individual choice and collective provision}

First, it is important to make explicit the tensions and conflicts articulated through the debates for and against DPs. In particular, it is necessary to develop a greater understanding of the implications and interaction between two seemingly conflicting, yet equally progressive, challenges for social policy. These positions relate to the primacy of ideologies of individual choice and collective provision. These two positions can be illustrated by the work of Stainton (2002) and O'Brien (2001). Stainton argues that the 'challenge for social policy is not to find better services, but to create a structure in which individuals can articulate their claims for the support they need to equalise their basic capacity to formulate and pursue self determined plans and purposes' (2002: 756). Alternatively, O'Brien emphasizes the necessity of providing the 'best conditions which will evolve and develop services that offer highly customized, specialized, publicly accountable, collective service provision and assistance' (2001: 2).

The development of social policy must ensure that both these progressive ideologies are facilitated in policy and practice. This could be possible through the development of communal resources such as the collective pooling of DPs (Maglajlic et al., 2000; Ridley and Jones, 2002; Stainton, 2002). It has been suggested that consumer cooperatives could be developed that would enable individuals to combine their DPs to purchase care collectively (Lewis, 2002). The cooperative would be the employer rather than just the individual recipient, thus reducing some of the employer-employee conflicts outlined above, while still enabling the DP recipient to be in control. Furthermore, pooling resources could enable the development of new services and community resources. It could also result in the collective use of contingency monies for members and training and support opportunities for PAs and recipients.

\section{b) Collective action for resources}

In a review of individualized funding schemes in Canada, the US and Australia, Lord and Hutchinson (2003) report that, where governments promoted individualized funding without resourcing community support networks in the non-profit sectors, it could result in a highly privatized system that limited the choice and control available to individuals. In addition, the extent to which recipients are able to 
exercise choice and control through DPs relies heavily on the availability of workers willing to work in the current context of relatively poor wages and conditions.

DPs therefore need to be adequately funded, both in terms of the actual packages, the pay rates available to PAs, as well as the support structures necessary to enable individuals and their communities to plan and implement their own support arrangements. Political action, community campaigning and collective negotiation may be necessary to entrench adequate levels of funding controlled by service users and their communities (National Union Research, 1998). Here, the discourse of consumerism is insufficient because, as O'Brien vividly describes, it is not as consumers but as political organizers, lobbyists, participants in civil disobedience, defendants . . . that people with disabilities and their families influence the level of money available to the current system' (2001: 6).

The promotion of DPs into other care groups may encourage and enable greater connections within and between different service user groups and social movements such as the disability and mental health user movement, where desire for greater collaboration has been thwarted (Beresford, 2000). Such connections could prove invaluable in the development of stronger and more unified action for greater resources and input into resource distribution. However, this transition must take into account the needs of workers in the system.

\section{c) Recipients and PAs}

It is necessary to acknowledge and address the complex dynamics and power relationships between recipients and PAs. The precarious situation of PAs, who are often isolated, marginalized and low paid, has been a concern for disability activists advocating DPs (see Ford and Shaw, 1992). However, this concern has not driven policy. Greater collaboration between the trade union movement and welfare user movements may result in developing alternative ways of organizing PAs if conventional ways are inappropriate. This may entail forms of occupational collectivity where membership is based not on the individual employer, but rather on the 'sense of solidarity developed through the work they perform' (National Union Research, 1998: 11). Informal networks of unorganized workers under DPs might provide a 'home base' for workers who are difficult to organize because of multiple work sites (National Union Research, 1998). Such initiatives 
could evolve as workers' cooperatives, but would have to be sensitive to, and vigilant about, the power dynamics between recipients and PAs. With these conflicts of interest in mind, Lewis (2002) suggests the development of 'multi stakeholder' cooperatives which would provide a structure through which DP recipients and PAs could openly discuss and negotiate key interests and could develop a powerful advocacy function, decrease individualization and maximize the pressure for adequate resources.

\section{d) Critical analysis}

The practice of DPs has disrupted traditional divisions between left and right political discourses and questioned many widely held assumptions and values about welfare provision. The resulting confusion demands a more critical understanding of the changing political context in which DPs are being implemented as well as more complex responses to their expansion. Finally, therefore, it is necessary to develop a critical understanding of the dominant political landscape in which DP schemes are being implemented and the ways this can open up - and close down - opportunities for the development of greater strategies for self-determination.

DPs exist within a constraining political culture which ultimately limits the extent to which they might be able to provide the wider benefits advocated by their proponents. Therefore, the extent of their progressiveness may ultimately depend not only on local implementation strategies, but also on these wider forces and, more importantly, how these forces are collectively negotiated, influenced and challenged. Although many of the tensions and contradictions discussed in this article have always been present in welfare services, DPs bring these into sharper focus. Careful consideration of the ways forward and sustained critique are necessary if DPs are really to function as 'one means to re-shape our world' (O'Brien, 2001: 15).

\section{Acknowledgements}

The author would like to thank Meg Allen, Carey Bamber, Erica Burman, Deborah Davidson, John Hopton, Jeremy Spandler and Nicky Vick for helpful comments on previous drafts of this article. 


\section{References}

6, P. (2003) 'Giving Consumers of British Public Services More Choice: What Can Be Learned from Recent History?', Journal of Social Policy 32(2): 239-70.

Bamber, C. (2002) 'Direct Payments for Mental Health Service Users', Mental Health and Occupational Therapy 7(3): 4-5.

Begum, N. (1992) 'Independent Living, Personal Assistance and Black Disabled People', pp. 51-4 in C. Barnes (ed.) Making Our Own Choice: Independent Living, Personal Assistance and Disabled People, report of the Nottingham British Council of Organisations of Disabled People seminar on Independent Living and Personal Assistance, Herewood College, Coventry, August.

Bennett, F. (1996) Highly Charged: Policy Issues Surrounding Charging for Nonresidential Care. York: Joseph Rowntree Foundation.

Beresford, P. (2000) 'What Have Madness and Psychiatric System Survivors Got to Do with Disability and Disability Studies?', Disability E Society 15(1): 167-72.

Beresford, P. (2002) 'User Involvement in Research and Evaluation: Liberation of Regulation?', Social Policy and Society 1(2): 95-105.

Brown, M. (1999) 'Service Please', Connections (Spring): 10-12.

Burman, E., Chantler, K. and Batsleer, J. (2002) 'Service Responses to South Asian Women who Attempt Suicide or Self Harm: Challenges for Service Commissioning and Delivery', Critical Social Policy 22(4): 641-68.

Campbell, J. (1997) 'Implementing Direct Payments: Towards the Next Millennium', pp. 22-34 in S. Balloch and N. Connelly (eds) Buying and Selling Social Care. London: National Institute for Social Work.

Campbell, J. (1998) 'From Breakout to Breakthrough: 25 Years of Legislative Advocacy', in B. Duncan and R. Berman-Bieler (eds) International Leadership Forum for Women with Disabilities: Final Report. New York: Rehabilitation International. [http://www.rehab-international.org/ publications/Leadership_Women/CAMPBELL.Jane.html]

Carmichael, A. and Brown, L. (2002) 'The Future Challenge for Direct Payments', Disability \& Society 17(7): 797-808.

DoH (Department of Health) (1996) Community Care (Direct Payments) Act: Policy and Practice Guidance. London: Stationery Office.

DoH (Department of Health) (2001a) Health and Social Care Act. London: Stationery Office.

DoH (Department of Health) (2001b) Modern Social Services - a Commitment to Deliver: The 10th Annual Report of the Chief Inspector of Social Services 2000/2001. London: Stationery Office. 
DoH (Department of Health) (2003) Direct Payments Guidance: Community Care, Services for Carers and Children's Services (Direct Payments) Guidance, England. London: Stationery Office.

Dowson, S. (2002) Not Just about the Money: Reshaping Social Care for Social Determination. Community Living and Emprise International Training and Consultancy.

Evans, J. (2000) 'Guidelines for Allocating Individual Funding: Making Sure it Is Fair', paper presented to the International Conference on Self Determination and Individualized Funding, Seattle, 29-31 July.

Fiske, E. B. and Ladd, H. F. (2000) When Schools Compete: A Cautionary Tale. Washington, DC: Brookings Institution.

Ford, C. and Shaw, R. (1992) 'The User/Personal Assistance Relationship', pp. 25-39 in C. Barnes (ed.) Making Our Own Choice: Independent Living, Personal Assistance and Disabled People, report of the Nottingham British Council of Organisations of Disabled People seminar on Independent Living and Personal Assistance, Herewood College, Coventry, August.

Glasby, J. and Littlechild, R. (2002) Social Work and Direct Payments. Bristol: Policy Press.

Glendinning, C., Halliwell, S., Jacobs, S., Rummery, K. and Tyer, J. (2000a) 'New Kinds of Care, New Kinds of Relationships: How Purchasing Affects Relationships in Giving and Receiving Personal Assistance', Health and Social Care in the Community 8(3): 201-11.

Glendinning, C., Halliwell, S., Jacobs, S., Rummery, K and Tyer, J. (2000b) 'Bridging the Gap: Using Direct Payments to Purchase Integrated Care', Health and Social Care in the Community 8(3): 192-200.

Glendinning, C., Halliwell, S., Jacobs, S., Rummery, K. and Tyer, J. (2000c) Buying Independence: Using Direct Payments to Integrate Health and Social Services. Bristol: Policy Press.

Gorard, S. and Taylor, C. (2002) 'Market Forces and Standards in Education: A Preliminary Consideration', British Journal of Sociology of Education 23(1): 6-18.

Halliwell, S. and Glendinning, C. (1998) Evaluation of the Manchester Direct Payments Scheme. Manchester: National Primary Care Research and Development Centre.

Harris, J. (1999) 'State Social Work and Social Citizenship in Britain: From Clientelism to Consumerism', British Journal of Social Work 29: 915-37.

Hasler, F. (1999) 'Exercising the Right to Freedom of Choice', Professional Social Work (June): 6-7.

Hasler, F., Campbell, J. and Zarb, G. (1999) Direct Routes to Independence: A Guide To Local Authorities Implementation and Management of Direct Payments. London: Policy Studies Institute. 
Henig, J. (1994) Rethinking School Choice: Limits of the Market Metaphor. Princeton, NJ: Princeton University Press.

Holman, A. (1999) 'Direct Payments: The Power to Empower', Llais (Autumn): 3-6.

Holman, A. and Bewley, C. (1999) Funding Freedom 2000: People with Learning Difficulties Using Direct Payments. London: Values into Action UK.

Kestenbaum, A. (1999) What Price Independence? Independent Living and People with High Support Needs. Bristol: Policy Press.

Lewis, F. (2002) 'Co-ops and Community Living', unpublished paper (December).

Lewis, L. (1998) 'Overview: The Personal Social Services', pp. 20-36 in A. O'Neil and D. Statham (eds) Shaping Futures: Rights, Welfare and Personal Social Services. London/York: National Institute for Social Work/Joseph Rowntree Foundation.

Lord, J. and Hutchinson, P. (2003) 'Individualised Support and Funding: Building Blocks for Capacity Building and Inclusion', Disability $\mathcal{E}$ Society 18(1): 71-86.

Maglajlic, R., Brandon, D. and Given, D. (2000) 'Making Direct Payments a Choice: A Report on the Research Findings', Disability \& Society 15(1): 99-113.

Maglajlic, R. A., Bryant, M., Brandon, D. and Given, D. (1998) 'Direct Payments in Mental Health: A Research Report', Breakthrough 2(3): 33-6.

Morris, J. (1993) Independent Lives? Community Care and Disabled People. Basingstoke: Macmillan.

Morris, J. (1997) 'Care or Empowerment? A Disability Rights Perspective', Social Policy and Administration 31(1): 54-60.

National Union Research (1998) The Hard Truth about Individualized Funding. Ontario: National Union of Public and General Employees.

National Union Research (2000) 'Self-managed Care and Individualised Funding Are Not the Same Thing!', paper presented to the Canadian Labour Congress Disability Rights conference, November.

Noden, P. (2000) 'Rediscovering the Impact of Marketisation: Dimensions of Social Segregation in England's Secondary Schools 1994-1999', British Journal of the Sociology of Education 21(3): 371-90.

O'Brien, J. (1999) Community Engagement: A Necessary Condition for Self Determination and Individual Funding. Georgia, USA: Responsive Systems Associates.

O'Brien, J. (2001) Paying Customers Are Not Enough: The Dynamics of Individualized Funding. Lithonia: Responsive Systems Associates.

O'Brien, J. and O'Brien, L. (1999) The Politics of Person Centred Planning. Georgia, USA: Responsive Systems Associates.

Pearson, C. (2000) 'Money Talks? Competing Discourses in the Implementation of Direct Payments', Critical Social Policy 20(4): 459-77. 
Ridley, J. and Jones, L. (2002) Direct What: A Study of Direct Payments to Mental Health Service Users. Edinburgh: Scottish Executive Central Research Unit.

Stainton, T. (1996) 'A Concept Tailor-made for People with Complex Needs', Community Living 9(4): 10-11.

Stainton, T. (2002) 'Taking Rights Structurally: Disability, Rights and Social Worker Responses to Direct Payments', British Journal of Social Work 32: 751-63.

Stainton, T. and Boyce, S. (2002) 'I Have Got My Freedom back: A Report on an Evaluation of Direct Payments in Cardiff and the Vale of Glamorgan', Llais 64: 3-5.

Torjman, S. (1996) Dollars for Services: A.k.a. Individualised Funding. Ontario: Caledon Institute of Social Policy.

Ungerson, C. (1997) 'Give Them the Money: Is Cash a Route to Empowerment?', Social Policy and Administration 31(1): 45-53.

UNISON (2001) Home Care: The Forgotten Service. London: UNISON.

UNISON (2002) 9th National Delegate conference, 18-21 June, Bournemouth.

Witcher, S., Stalker, K., Roadburg, M. and Jones, C. (2000) Direct Payments: The Impact on Choice and Control for Disabled People. Edinburgh: Scottish Executive Central Research Unit.

Zarb, G. (1998) 'What Price Independence?', paper presented at Shaping Our Futures: A European Network on Independent Living. London

Zarb, G. (2003) 'High Court Ruling on Care Workers Refusing to Lift Disabled People', Hampshire County Council direct payments newsletter 114.

Zarb, G. and Nadash, P. (1994) Cashing in on Independence: Comparing the Costs and Benefits of Cash and Services for Meeting Disabled People's Support Needs. Derby: BCODP/PSI.

- Helen Spandler was research associate at King's College, London, working with the Health and Social Care Advisory Service. She evaluated a national pilot project to implement DPs for people with mental health needs. She has recently completed a $\mathrm{PhD}$ at the discourse unit, department of psychology and speech pathology, Manchester Metropolitan University. Her thesis was about the history of therapeutic communities and the mental patient movement. She is on the editorial collective of Asylum: The Magazine for Democratic Psychiatry. Address: c/o Health and Social Care Advisory Service, 11-13 Cavendish Square, London W1G OAN. email: h.spandler@ntlworld.com $\square$ 